\title{
Intelligent NFC potassium measurement strip with hemolysis check in capillary blood
}

C. Kollegger, P. Greiner, I. Siegl, C. Steffan, M. Wiessflecker, B. Pekec, M. Hajnsek, F. Sinner, G. Holweg, B. Deutschmann

\begin{abstract}
130 million people in Western Europe and the USA suffer from chronic cardiac degeneration or kidney insufficiency. The medical treatment requires a routine medical examination accompanied by laboratory blood analyses. This is cost-intensive for the health care system and also time consuming for the patients. This paper presents an economical, wireless sensor node solution in terms of an intelligent near field communication (NFC) potassium measurement strip (NPMS) usable in a home environment. The NPMS comprises two different electrochemical sensors for the acquisition of two parameters in capillary blood and an autonomous sense and identification grain (ASIG) for the electrical analysis, communication, and data transfer. The ASIG is equipped with an integrated amperometric and potentiostatic functionality, radio frequency identification (RFID) interface for high frequency (HF)/NFC, and has been designed using a $130 \mathrm{~nm}$ CMOS standard process. It facilitates the implementation of two different measurement techniques, which are necessary for the accurate determination of the potassium concentration in capillary blood, whereby the occurrence of hemolysis can be detected. This NPMS impresses with its large scale integration and is solely powered by the NFC reader device.
\end{abstract}

Keywords: NFC; amperometry; potentiometry; CMOS

Intelligenter NFC-Kalium-Messstreifen mit Hämolysekontrolle in Kapillarblut.

130 Millionen Menschen in Westeuropa und den USA leider an chronischer Herz- oder Niereninsuffizienz. Die Behandlung erfordert eine regelmäßige medizinische Untersuchung, welche mit Laboranalysen des Blutes einhergeht. Dies ist kostenintensiv für das Gesundheitswesen und auch zeitaufwendig für den Patienten. Dieser Beitrag präsentiert eine ökonomische, drahtlose Sensorknotenlösung in Form eines intelligenten NFC-Kalium-Messstreifens (NPMS) für den Heimgebrauch. Der NPMS enthält zwei verschiedene elektrochemische Sensoren für die Erfassung zweier Parameter im Kapillarblut und einen autonomen Mess- und Identifikations-Chip (ASIG) für die elektrische Analyse, die Kommunikation und den Datentransfer. Der ASIG verfügt über eine integrierte amperometrische und potentiostatische Funktionalität, ein RFID Interface für HFINFC und wurde mit einem $130 \mathrm{~nm}$ CMOS-Standardprozess hergestellt. Er ermöglicht die Durchführung zweier verschiedener Messmethoden, die für die genaue Bestimmung der Kaliumkonzentration im Blut notwendig sind, wobei das Auftreten von Hämolyse detektiert werden kann. Dieser NPMS beeindruckt durch seinen hohen Integrationsgrad und wird ausschließlich durch das NFC-Lesegerät versorgt.

Schlüsselwörter: NFC; Amperometrie; Potentiometrie; CMOS

Received September 8, 2017, accepted December 26, 2017, published online January 23, 2018

(C) The Author(s) 2018. This article is published with open access at Springerlink.com

\section{Introduction}

The leading cause of death in the United States and worldwide is cardiovascular disease, which is responsible for great human suffering and enormous healthcare costs [1]. The American Heart Association seeks to prevent such diseases effectively by recommending various effective measures for maintaining a heart healthy. These include regular exercise, heart-healthy diets, and the cyclical control of blood parameters [2].

A regular medical examination is currently necessary for patients suffering from chronic cardiac degeneration or kidney insufficiency. A whole blood sample is taken as a matter of routine and various blood parameters are analyzed. The blood potassium level in particular is diagnostically conclusive regarding patient health condition.

Hemolysis can occur during a blood extraction, which leads to a falsified measurement result. Pressure on the skin-surface during the sampling process can burst erythrocytes and their high potassium and also hemoglobin concentration is released. The large quantity of released potassium can falsify the result of the potassium amount in blood plasma.

To avoid such negative effects the blood sample taking needs to be performed by healthcare professionals in a laboratory environment with measurement equipment such as e.g. Reflotron ${ }^{\circledR}$ Plus.

Kollegger, Carolin, Infineon Technologies Austria AG, Development Center Graz, Babenbergerstraße 10, 8020 Graz, Austria (E-mail: carolin.kollegger-ee@infineon.com); Greiner, Philipp, Graz University of Technology, Institute of Microwave and Photonic Engineering, Graz, Austria; Siegl, Inge, Infineon Technologies Austria AG, Development Center Graz, Babenbergerstraße 10, 8020 Graz, Austria; Steffan, Christoph, Infineon Technologies Austria AG, Development Center Graz, Babenbergerstraße 10, 8020 Graz, Austria; Wiessflecker, Martin, Infineon Technologies Austria AG, Development Center Graz, Babenbergerstraße 10, 8020 Graz, Austria; Pekec, Bruna, Joanneum Research Health, Graz, Austria; Hajnsek, Martin, Joanneum Research - Health, Graz, Austria; Sinner, Frank, Joanneum Research - Health, Graz, Austria; Holweg, Gerald, Infineon Technologies Austria AG, Development Center Graz, Babenbergerstraße 10, 8020 Graz, Austria; Deutschmann, Bernd, Graz University of Technology, Institute of Electronics, Graz, Austria 
However, due to the required high sample volume of at least $30 \mu \mathrm{l}$ of whole blood and the high costs involved, a device of this kind is not suitable for home usage self-testing. Furthermore, a qualified medical employee must perform the blood draw from a vein in order to avoid hemolysis.

This current patient care provision in a clinical environment leads to additional risks due to long control interval times. Furthermore, an increase of these chronic health conditions and the dangers and costs involved have led to the requirement for domestic control appliances. The possibility of performing measurements in a domestic environment would improve life quality for patients.

In recent years, enormous efforts have been expended on the design and development of various disposable electrochemical sensors, suitable for domestic assessment of blood parameters. Jiang et al. [3] presents a good solution for hemoglobin determination in whole blood based on an amperometric detection technology. Cafferty [4] also elaborated this subject by using impedance spectroscopy, whereby no erythrocytes separation is necessary.

This paper presents an intelligent near field communication (NFC) potassium measurement strip (NPMS) with hemolysis check in capillary blood. The small blood sample volume of approximately $5 \mu \mathrm{l}$ in combination with a novel hemolysis detection makes it suitable for home usage and self-testing. Due to the increased frequency of blood potassium level measurements the patient's medical risk can be reduced, and health-related quality of life can be enhanced. In addition costs can be cut significantly as no healthcare professionals are required. Furthermore, the prototype presented is suitable for mass production

This paper is organized as follows. Section 2 presents the intelligent NPMS concept, the working principle of the different parts and their connection. Section 3 describes the chemical sensor, its structure, and an overview of the sensor chemistry. Section 4 explains in more detail the procedure of the measurement principle including the potentiostatic potassium measurement and the amperometric hemolysis detection. Section 5 gives a description of the set-up of the NPMS prototype which is a disposable strip solution. Section 6 presents measurement results. The conclusion can be found in Sect. 7.

\section{Concept of the intelligent NPMS}

\subsection{General description of the system}

The intelligent NPMS consists of an ion-selective electrode (ISE) sensor, an autonomous sense and identification grain (ASIG) and an antenna for communication. The silk-screened ISE sensor is comprised of two separate sensor technology parts, one for potassium and the second for hemolysis measurement, whereby initially the blood sample erythrocytes separation is performed by a specific filter membrane. Five silver (Ag)/silver-chloride $(\mathrm{AgCl})$ electrodes connect the sensitive part with the ASIG chip. Three electrodes connect the hemolysis sensor with the amperometric sensor interface, the other two potassium sensor electrodes are connected to the built-in high impedance potentiostat of the ASIG.

The ASIG constitutes a passive high frequency (HF) radio frequency identification chip which uses the ISO/IEC 14443 Type A contactless smart card standard for communication and operates at a frequency of $13.56 \mathrm{MHz}$. It has an active chip area of about $5 \mathrm{~mm}^{2}$. The concept for an implementation of the intelligent NPMS, suitable for the determination of the potassium concentration in capillary blood, is illustrated in Fig. 1. The ASIG is connected via

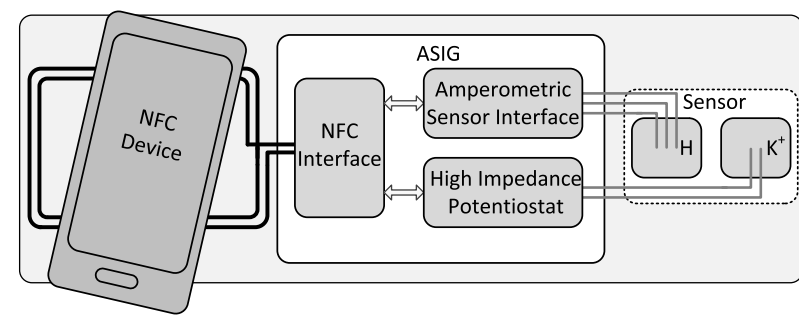

Fig. 1. Overall concept of the intelligent NPMS: it consists of an ISE sensor part, an ASIG and an antenna for communication. The ISE sensor comprises a potassium $\mathrm{K}^{+}$and a hemolysis $(\mathrm{H})$ sensor. The NPMS is powered passively using an NFC reader device

two bond wires to the antenna, implemented on a flexible printed circuit board (PCB) and powered solely by the NFC field. It consists of an NFC interface, an amperometric sensor interface, and a high impedance potentiostat.

The NFC interface is active as soon as the system is in the communication range of an NFC reader device and the ASIG is powered passively. A bidirectional communication between the ASIG and the NFC reader device is established in compliance with the ISO 14443 protocol standard. The sensor interface of the ASIG can be configured via NFC, allowing control the measurement procedure as also the potentiostatic and amperometric interfaces. A precision bandgap, an 11-bit successive approximation register analog to digital converter [5], plus precision reference resistors are implemented to assure accurate measurement.

The high impedance potentiostat is connected via two ports to the potassium sensor. It measures the potential difference between reference and working electrode of the sensor, which depends on the potassium concentration in the sample, in accordance with the Nernst equation (see Sect. 4.1)

The amperometric sensor interface takes on a control function for the correct blood extraction (see Sect. 4.2). It is connected via a working, auxiliary, and a reference electrode with the hemolysis sensor. A defined potential of $0.5 \mathrm{~V}$ between working and reference sensor electrode is adjusted, and the current flowing from auxiliary to working electrode is measured via a shunt resistor. This current is a marker for the hemolysis level in the blood sample, whereby an incorrect blood extraction with a high level of hemoglobin and also potassium can be detected.

The measurement itself is triggered by an NFC device and an appropriate Android ${ }^{\mathrm{TM}}$ application. The potentiostatic and amperometric sensors are evaluated separately for each potassium acquisition. The result of the potassium measurement is only displayed, however, when the hemolysis check is passed. If it is not passed, a repetition of the procedure (blood extraction and measurement) is recommended.

\section{Ion-selective sensors}

\subsection{Potassium sensor}

The potassium sensor is based on the ion-sensitive electrode (ISE) concept and comprises a potassium sensitive working electrode and an $\mathrm{Ag} / \mathrm{AgCl}$ reference electrode. The working electrode is a screenprinted carbon electrode covered by a potassium sensitive membrane with valinomycine as ionophore. Both electrodes and the potassium sensitive membrane are screen-printed and allow high volume sensor fabrication. 


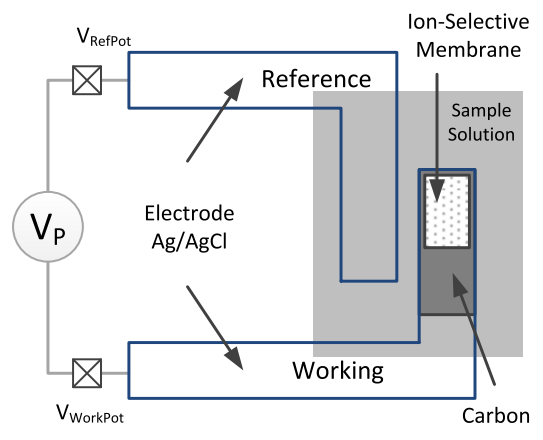

Fig. 2. Potentiostatic measurement principle: the built-in high impedance potentiostat $V_{P}$ is connected to the working and reference electrode of the potassium sensor. The potassium concentration of the sample solution is gathered by an electrical potential

\subsection{Hemolysis sensor}

The amperometric hemolysis sensor is configured as three electrode system with an $\mathrm{Ag} / \mathrm{AgCl}$ reference electrode and a carbon auxiliary electrode. The working electrode is a modified carbon electrode that allows selective redox interaction with free hemoglobin in the sample delivering a hemolysis dependent electrical current as sensor signal. The electrodes are screen-printed and are printed with the electrodes of the potassium sensors which in turn reduces fabrication steps.

\section{ASIG measurement principle for potassium and hemolysis detection}

\subsection{Potentiostatic measurement}

The concentration of potassium in the extracellular fluid is a critical determinant of the resting membrane potential of cells and must be maintained within a narrow range, normally between $3.5 \mathrm{mM}$ and $5 \mathrm{mM}$ in plasma concentration [6]. The detection of anomalies in the potassium level of patients in a precarious condition is thus essential.

The working $V_{\text {WorkPot }}$ and reference $V_{\text {RefPot }}$ electrodes of the potassium sensor are connected with the high impedance potentiostat $V_{P}$ (see Fig. 2) which constitutes a rail-to-rail output folded cascode operational amplifier, and a buffer stage, limiting the input bias current to $1 \mathrm{pA}$. The reference electrode is used to provide a reference to measure the potential. The ion-selective working electrode is a sensor or transducer that converts the activity of the potassium ion $\mathrm{K}^{+}$into an electrical potential. In accordance with the Nernst equation (see Eq. (1)), which defines the dependency of the electrode potential and the potassium activity, the voltage is dependent on the logarithm of the ionic activity.

$$
E=E^{0}+\frac{R T}{z_{\mathrm{e}} F} \ln a_{K}+
$$

\subsection{Hemolysis detection-amperometry}

Figure 3 shows a schematic representation of the amperometric sensor interface. This interface can be used for carrying out the voltammetry analytical method, which is the representation of the current as a function of the applied potential $[7,8]$. It has three connections to the sensor electrodes: $V_{\text {WorkAmp }}, V_{\text {RefAmp }}$, and $V_{\text {AuxAmp }}$. The voltage at the ion-selective working electrode $V_{\text {WorkAmp }}$ can be controlled and the current $I_{H}$ flowing in or out of this node can be determined via the voltage drop across an adjustable shunt resistor

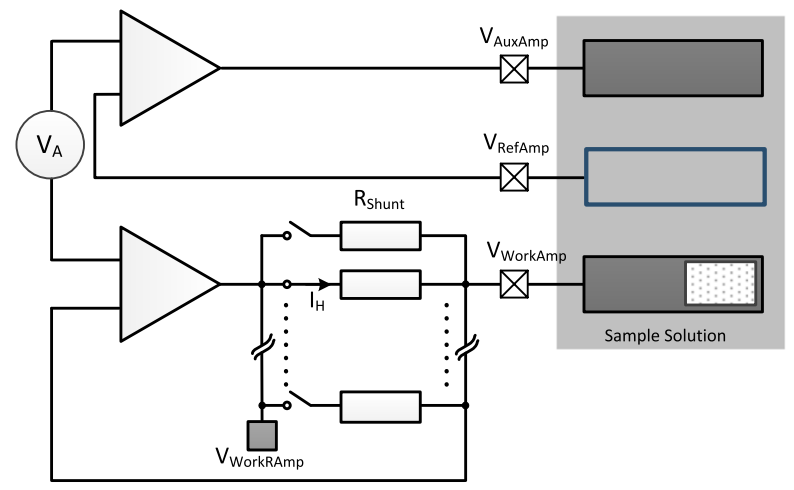

Fig. 3. Schematic representation of the amperometric sensor interface: it is connected to the auxiliary, reference and working electrode of the hemolysis sensor. The voltage drop at $V_{\text {WorkAmp }}$ can be controlled and the current $I_{H}$ is determined

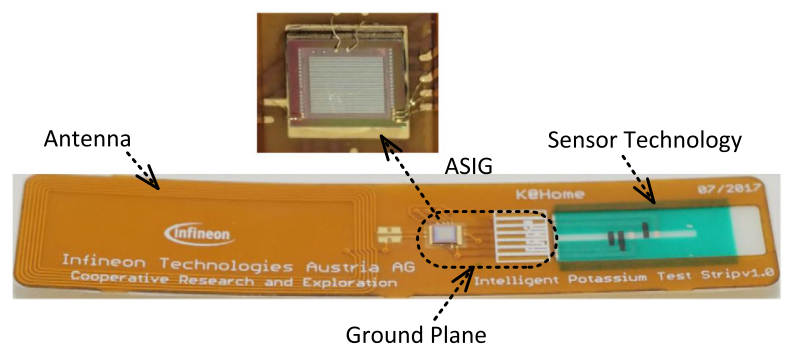

Fig. 4. Illustration of the flexible PCB NPMS solution: the analog circuitry including the integrated antenna is manufactured using a flexible PCB which is connected to the sensor. The chip is wire bonded and additionally protected using an epoxy glob top (not illustrated here)

$R_{\text {Shunt }}$ using Eq. (2)

$$
I_{H}=\frac{V_{\text {WorkRAmp }}-V_{\text {WorkAmp }}}{R_{\text {Shunt }}}
$$

The voltage at the reference node $V_{\text {RefAmp }}$ is monitored and regulated to a specific configurable voltage $V_{A}$. The voltage $V_{\text {RefAmp }}$ is not directly steered as this node should never carry electrical current. The voltage is controlled indirectly by adjusting the voltage at the auxiliary node $V_{\text {AuxAmp }}$.

\section{Prototype of the NPMS}

Figure 4 shows a picture of the first NPMS prototype which has dimensions of $74 \mathrm{~mm} \times 15 \mathrm{~mm}$. A thin polyethylene terephthalate (PET) foil sheet serves as a carrier for the sensor technology. The analog circuitry including the integrated antenna is fabricated on a $60 \mu \mathrm{m}$ flexible PCB foil, which is glued to the carrier. The ASIG chip has been wire bonded to the flexible PCB and an additional epoxy glob top (for the purpose of illustration not used in this setup) serves as a protector for the fragile bond wires. Additionally a ground plane is positioned around the sensitive data acquisition area to reduce outside interference. The antenna coil is implemented with six windings and is tuned to the resonant frequency of $13.56 \mathrm{MHz}$ using a $100 \mathrm{pF}$ resonant capacitor. Further, its placement separate from the sensors makes the handling easier for the patient, because the NFC reader device can be placed directly on the antenna without coming into contact with the blood sample. 


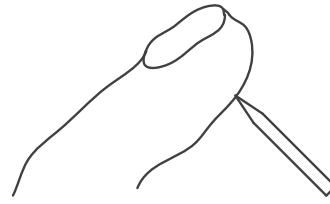

(a) Blood caption using a lancing device.

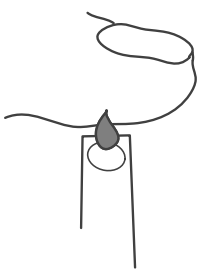

(c) Application of the blood drop to the plasma separation membrane filter.

Fig. 5. Depiction of the blood sampling test sequence: from blood caption to measurement readout using an NFC device

\section{Measurement procedure and results}

\subsection{Test sequence}

The test sequence for the usage of the intelligent NPMS is straightforward and easy to handle. The aim is to obtain a quantitative determination of potassium in human blood by screening capillary blood. Figure 5 illustrates the necessary steps. Initially, the patient pricks a finger using a lancing device to obtain a capillary blood sample-see Fig. 5(a). The first blood drop must not be used since skin particles or cells could falsify the result. Figure $5(\mathrm{~b})$ demonstrates a smooth finger massage from back to tip which should be performed with minimum pressure.

The blood sample is applied to the plasma separation membrane, which is shown in Fig. 5(c). This filter captures the cellular components of the blood (red cells, white cells, and platelets) without lysis, while the plasma flows to the membrane. Subsequently, the plasma sample is drawn via a micro-channel to the potassium and hemolysis sensor for consecutive analysis. Finally, the measurement process is performed and the results are displayed on an Android ${ }^{\mathrm{TM}}$ smart phone, see Fig. 5(d).

\subsection{Potentiostatic measurement}

Figure 6 shows the transient voltage measured by means of the potentiostat. After applying the blood sample a transient response can be observed, which after 100 seconds settles to a voltage representing the potassium concentration of $1 \mathrm{mmol} / \mathrm{l}$. The voltage value is taken after a defined settling time of 120 seconds for the potassium measurement.

The potentiostatic potassium measurement has been performed for several devices using four test liquids with defined potassium concentrations of $1,4,7$, and $10 \mathrm{mmol} / \mathrm{l}$. As expected, a logarithmic

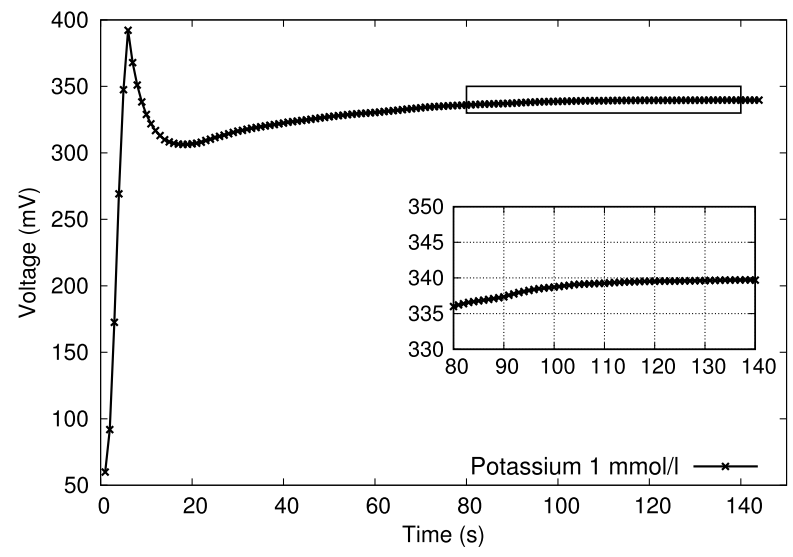

Fig. 6. Potentiostatic result of the potassium measurement of $1 \mathrm{mmol} / \mathrm{l} \mathrm{K} \mathrm{K}^{+}$test solution: after a defined settling time of $120 \mathrm{sec}$ onds the measured voltage value represents the potassium concentration

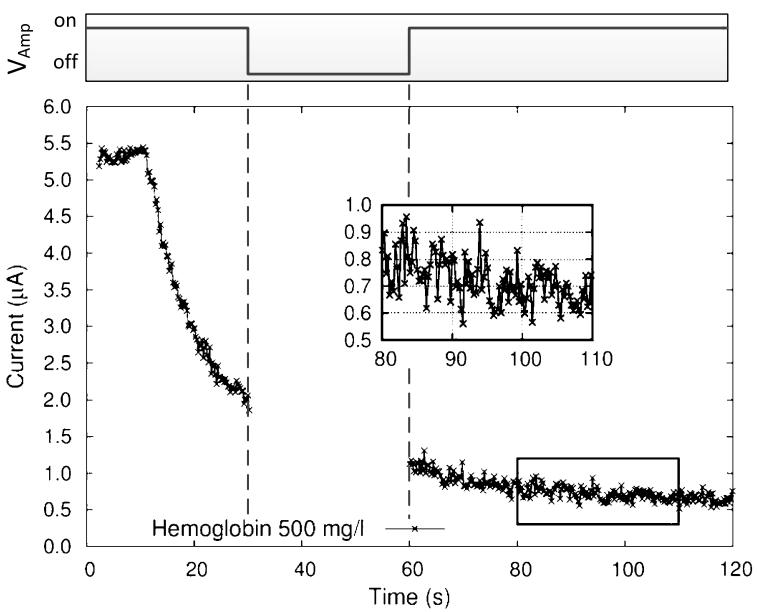

Fig. 7. Amperometric result of the hemolysis measurement employing $500 \mathrm{mg} / \mathrm{l}$ hemoglobin test solution: as the sensor chemistry needs a trigger and settling time, $\boldsymbol{V}_{\text {Amp }}$ needs to be turned off for $30 \mathrm{sec}$ onds. The current, measured after 90 second, can be converted into a hemoglobin concentration

relationship between the measured voltage and the potassium concentration was observed. Further investigations are required in order to define the potassium concentration as a function of the voltage as well as the achievable accuracy.

\subsection{Amperometric measurement}

Figure 7 demonstrates the transient behavior of the sensor during the measurement process. A defined hemoglobin test solution of $500 \mathrm{mg} / \mathrm{l}$ was used to demonstrate the behaviour of the hemolysis sensor and the amperometric sensor interface. Initially the NPMS is powered thus triggering the sensor chemistry so it can react in the background. After 30 seconds the configurable voltage $V_{A m p}$ is turned off because the sensor needs some equilibration time. 30 seconds later $V_{A m p}$ is switched on again and after a sensor settling time of about 30 seconds a constant current can be observed. The threshold current for the hemolysis detection must be set using empiric measurements in the course of a sensor calibration process. 


\section{Conclusion}

An intelligent, disposable blood analysis strip has been implemented. The authors presented a single-chip solution merged with a dual purpose electrochemical sensor for a blood potassium determination for use in a domestic environment. The device is suitable for mass production, because of the simple set-up and minimal number of components. Patient risks from potassium lapses can be reduced significantly by means of the simple and effective regular potassium level check that can be provided by this means.

\section{Acknowledgements}

Open access funding provided by Graz University of Technology. This work was supported by the Austrian Research Promotion Agency (FFG) within the 'K@Home - Kalium Home Monitoring' project and has been carried out in cooperation with the Graz University of Technology, the Medical University of Graz, Joanneum Research Health, and Infineon Technologies Austria AG.

Open Access This article is distributed under the terms of the Creative Commons Attribution 4.0 International License (http://creativecommons.org/ licenses/by/4.0/), which permits unrestricted use, distribution, and reproduction in any medium, provided you give appropriate credit to the original author(s) and the source, provide a link to the Creative Commons license, and indicate if changes were made.

\section{References}

1. Arnett, D. K., Goodman, R. A., Halperin, J. L., Anderson, J. L., Parekh, A. K., Zoghbi, W. A. (2014): AHA/ACC/HHS strategies to enhance application of clinical practice guide-

\section{Authors}

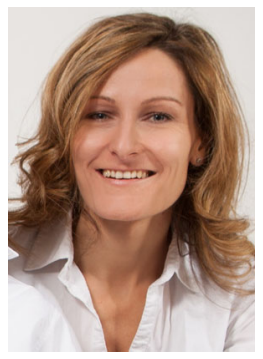

\section{Carolin Kollegger}

received her M.Sc. degree in Telematics from the Graz University of Technology, Austria, in 2006. Her graduate research focused on phase measurements and background correction of opto-chemical sensors. After six years operating in the logistic sector she started working at Infineon Technologies Austria AG, Graz, in 2012. Since 2014 she has been currently pursuing the Ph.D. degree concentrating on various (bio-) medical systems and applications.

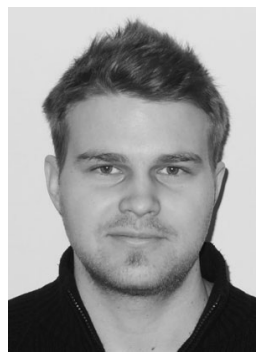

\section{Philipp Greiner}

was born in Graz, Austria, in 1986. He received his B.Sc. and M.Sc. degrees in electrical engineering from the Graz University of Technology, Austria, in 2011 and 2013, respectively. His graduate research focused on NFC-RFID with emphases on analog integrated circuits. In 2017, he received his Dr. techn. (Ph.D.) degree with honors from Graz University of Technology. In his Ph.D. thesis, he was working in the area of wireless miniaturization with special focus on highly stable all CMOS frequency generation for crystal quartz replacement. Since then he has been working on various industrial research and development projects focusing on sense and control applications. lines in patients with cardiovascular disease and comorbid conditions: from the American Heart Association, American College of Cardiology, and U.S. Department of Health and Human Services. J. Am. Coll. Cardiol., 64, 1851-1856.

2. Benjamin, E. J. Blaha, M. J, Chiuve, S. E Cushman, M. Das, S. R, Deo, R de Ferranti, S. D., Floyd, J., Fornage, M., Gillespie, C., Isasi, C. R., Jiménez, M. C., Chaffin Jordan, L., Judd, S. E., Lackland, D., Lichtman, J. H., Lisabeth, L., Liu, S., Longenecker, C. T., Mackey, R. H., Matsushita, K., Mozaffarian, D., Mussolino, M. E., Nasir, K., Neumar, R. W., Palaniappan, L., Pandey, D. K., Thiagarajan, R. R., Reeves, M. J., Ritchey, M., Rodriguez, C. J., Roth, G. A., Rosamond, W. D., Sasson, C., Towfighi, A., Tsao, C. W., Turner, M. B., Virani, S. S., Voeks, J. H., Willey, J. Z., Wilkins, J. T., Wu, J. H. Y., Alger, H. M., Wong, S. S., Muntner, P. (On behalf of the American Heart Association Statistics Committee and Stroke Statistics Subcommittee) (2017): Heart disease and stroke statistics-2017 update: a report from the American Heart Association. Circulation, 135, e146-e603.

3. Jiang, L., Luo, X., Tian, Q., Wang, H., Cai, X. (2006): Disposable biosensor for hemoglobin determination in whole blood. In Proc. 1st IEEE int. conf. nano/micro engineered and molecular systems (pp. 204-208).

4. Cafferty, M. (2014): Hemolysis detection method and system. WO 2015178924 A1.

5. Wiessflecker, M., Hofer, G., Holweg, G., Pribyl, W. (2012): An 11 bit SAR ADC combining a split capacitor array with a resistive ladder and a configurable noise time domain comparator. In Proc. IEEE 55th int. Midwest symp. circuits and systems (MWSCAS) (pp. 101-104).

6. Cheng, C.-J., Kuo, E., Huang, C.-L. (2013): Extracellular potassium homeostasis: insights from hypokalemic periodic paralysis. Semin. Nephrol., 33, 237-247.

7. Lauwers, E., Suls, J., Gumbrecht, W., Maes, D., Gielen, G., Sansen, W. (2001): A CMOS multiparameter biochemical microsensor with temperature control and signal interfacing. IEEE J. Solid-State Circuits, 36(12), 2030-2038.

8. Levine, P. M., Gong, P., Levicky, R., Shepard, K. L. (2008): Active CMOS sensor array for electrochemical biomolecular detection. IEEE J. Solid-State Circuits, 43(8), 1859-1871.

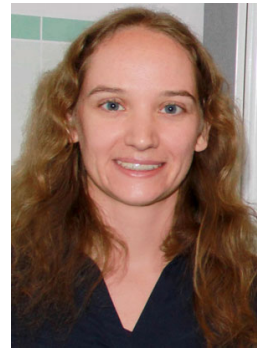

Inge Siegl

studied electrical engineering at the Graz University of Technology, Austria, and received her M.Sc. degree in 2016. Currently, she is pursuing her dissertation in cooperation with Infineon Technologies Austria AG. There she supports measurement procedures for various chemical sensors on the electronic side. Her thesis in the field of analog integrated circuit design focuses on the further development of a suitable integrated sensor interface for (bio-) chemical sensors

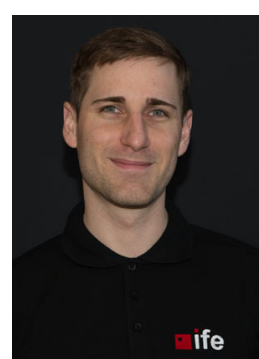

\section{Christoph Steffan}

was born in Graz, Austria, in 1986. He received his B.Sc. and M.Sc. degrees in electrical engineering from the Graz University of Technology, Austria in 2011 and 2013, respectively. His graduate research focused on DC to DC converters with emphases on analog integrated circuits. Since then he has been working toward the Ph.D. degree in the area of integrated energy harvesting interfaces with special focus on ultra-low power designs for autonomous wireless sensor nodes. 


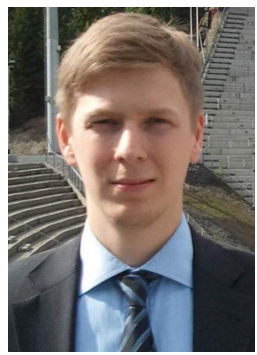

\section{Martin Wiessflecker}

was born in Graz, Austria, in 1985. He started his studies of electrical engineering in 2004 at the Graz University of Technology. He finished his Bachelor of Science in 2009 and continued his studies for a Master of Science in electrical engineering with focus on analog chip design. After finishing his master's study in 2010, he started working at Infineon Austria Technologies AG to do research and write a Ph.D. thesis on wireless sensors which he completed in 2013. Since 2014 he has been working as an application engineer in Japan at DICE GmbH \& Co KG which is majority owned by Infineon Technologies to support customers in the RADAR and TPMS businesses.

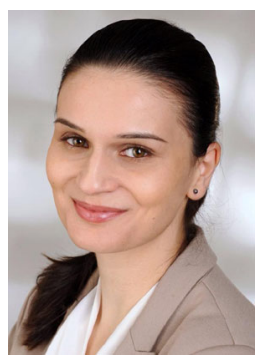

\section{Bruna Pekec}

received her Ph.D. in analytical chemistry from the Institute of Pharmaceutical Sciences, Karl-Franzens University of Graz, Austria. She has seven years of experience in the development of methods for medical, pharmaceutical and environmental analysis. She is specialized on electrochemistry and sensor development. At her current position at the Joanneum Research's HEALTH-Institute for Biomedicine and Health Sciences she designs medical home monitoring systems and test strips for clinical diagnostics.

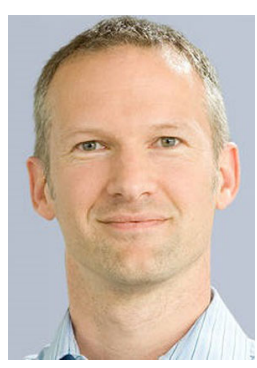

\section{Martin Hajnsek}

received his Ph.D. in analytical chemistry from the Graz University of Technology, Austria. He gained ten years of experience in $R \& D$ in the medical device industry before he joined Joanneum Research in 2010. He is currently working as a senior scientist at Joanneum Research's HEALTH-Institute for Biomedicine and Health Sciences. His current research interests are medical device development based on innovative optical and electrochemical sensor technologies.

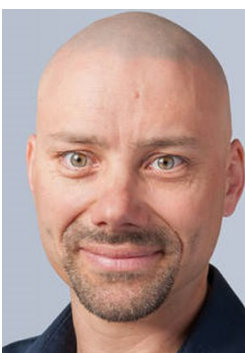

\section{Frank Sinner}

received his Ph.D. in analytical chemistry from the Institute of Analytical Chemistry and Radiochemistry, University of Innsbruck, Austria. He is director of the HEALTH Institute for Biomedicine and Health Sciences at Joanneum Research, Graz, Austria, and science group leader of the medical sensors group. His current research interest is focused on pharmaceutical and medical technology research including electrochemical sensors.

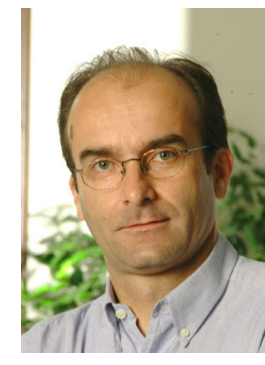

\section{Gerald Holweg}

received his master's degree in electronic engineering from the Graz University of Technology in 1983 and started his professional career as ASIC design engineer at AMIAustria. In 1987 he joined start-up company Mikron-Austria as project manager for RFID ASICS. In 1995, he took the position of development manager for the product line contactless smart cards at Mikron, which joined Philips in June 1995. In 1998 he started working as director of development for chip card and security ICS at start-up design centre Siemens Entwicklungszentrum für Mikroelektronik in Graz, which changed to Infineon Technologies Development Centre in 1999. Since 2003 he has been responsible for predevelopment programs and industrial research projects.

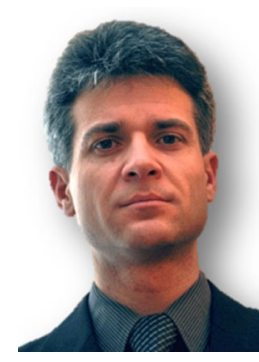

\section{Bernd Deutschmann}

received his M.Sc. degree and the Ph.D. degree in telecommunication engineering from the Graz University of Technology, Austria, in 1999 and 2002, respectively. Between 2000 and 2006, he was with austriamicrosystems AG, Austria, as a senior EMC task force engineer. From 2006 to 2013, he held the position of senior staff EMC expert with Infineon Technologies AG in Munich, Germany. He is currently a full professor with the Graz University of Technology, as the head of the Institute of Electronics. His research interests include EMC design for integrated circuits, power electronics, and EMC simulation and measurement techniques. During his research activities, he has applied for several patents and has authored and co-authored numerous papers and technical articles in the field of electromagnetic compatibility of integrated circuits. 